\title{
Upper Respiratory Tract Infection
}

National Cancer Institute

\section{Source}

National Cancer Institute. Upper Respiratory Tract Infection. NCI Thesaurus. Code C35650.

An infectious process affecting the upper respiratory tract (nose, paranasal sinuses, pharynx, larynx, or trachea). Symptoms include congestion, sneezing, coughing, fever, and sore throat. 